\title{
Radiographic osteoporotic vertebral fractures in elderly men: a brief review focusing on differences between the sexes
}

\author{
Yì Xiáng J. Wáng ${ }^{1}$, Brian C. Lentle ${ }^{2}$ \\ ${ }^{1}$ Department of Imaging and Interventional Radiology, Faculty of Medicine, The Chinese University of Hong Kong, Shatin, New Territories, Hong \\ Kong, China; ${ }^{2}$ Department of Radiology, University of British Columbia, Vancouver, BC, Canada \\ Correspondence to: Dr. Yì Xiáng J. Wáng. Department of Imaging and Interventional Radiology, Faculty of Medicine, The Chinese University of \\ Hong Kong, Shatin, New Territories, Hong Kong, China. Email: yixiang_wang@cuhk.edu.hk.
}

\begin{abstract}
Bone loss occurs in both sexes as a result of ageing but is exacerbated in women by the hormonal changes associated with menopause. Unlike in women, secondary osteoporosis occurs in almost half of men diagnosed with osteoporosis. Moreover, vertebral fractures (VFs) seen in elderly men may more likely be the result of high energy trauma. The osteoporotic vertebral fracture (OVF) radiograph diagnosis criteria for women may not be directly applicable for men. Particular attention should be paid to the mid-thoracic level where over-diagnosis commonly occurs. For wedge-shaped vertebral deformities (VDs) or VDs with anterior height reduction only, a diagnosis of OVF requires great caution, as they are poorly correlated to bone mineral density (BMD). For age-matched subjects, it is likely that elderly men's prevalent radiographic OVFs are approximately half of the elderly women's. This male-female ratio is very similar to other clinical fractures such as those occurring at the hip. Even so, the clinical relevance of OVF in elderly men may be less than that of elderly women. On the other hand, for elderly men with hip BMD-based osteoporosis, the OVF risk is as high as that of osteoporotic women. Elderly Chinese men have a lower OVF prevalence than age-matched Caucasian men.
\end{abstract}

Keywords: Osteoporosis; vertebral fracture (VF); radiograph; progression; incidence; men; women

Submitted Jun 20, 2020. Accepted for publication Jun 28, 2020.

doi: 10.21037/qims-2020-21

View this article at: http://dx.doi.org/10.21037/qims-2020-21

\section{Introduction}

Over recent decades, osteoporosis has evolved from being considered as an inevitable consequence of ageing, to being recognized as an important and treatable disease. Osteoporotic vertebral fractures (OVFs) are the most common osteoporotic fracture. Appropriate interventions can reduce the occurrence of osteoporotic fractures, reducing pain and related disabilities (1-5). It is important to identify OVF, so that appropriate investigation, prevention, and treatment can be instigated, both for women and men (6). Osteoporosis affects men differently from women in a number of respects. Bone loss occurs in both sexes as a result of ageing but is exacerbated in women by the hormonal changes associated with the menopause.
Differences in skeletal size, mechanical loading and muscle mass also play a role in the patterns of bone loss in men and women.

Unlike in women in whom it is much rarer, secondary osteoporosis occurs in almost half of men diagnosed with osteoporosis $(7,8)$. Major causes include hypogonadism due to treatment for prostate carcinoma with androgen withdrawal therapy, primary hyperparathyroidism, alcohol abuse, as well as glucocorticoid therapy for arthritis or asthma. For the diagnosis of osteoporosis in elderly men, a complete history and physical examination is essential and may reveal remediable disorders (7-9). Moreover, a vertebral fracture (VF) seen in elderly men may more likely be associated with high energy trauma. In their studies with 10 years' follow-up (FU), Ensrud et al. (10) reported that 
although the majority of major osteoporotic fracture (MOF) events in each sex were classified as low energy trauma with most resulting from a fall from standing height or less, these proportions were lower in men compared with women ( $82 \%$ of MOF in men $v s .93 \%$ of MOF in women). MOF events were more commonly classified as related to high energy trauma in men compared with women $(14.6 \%$ of MOF in men vs. $6.3 \%$ of MOF in women). MOF classified as moderate trauma also occurred more frequently in men compared with women ( $3 \%$ of MOF in men $v s .1 \%$ of MOF in women).

Much is known about OVF in women but OVF in men have been less well studied. This review focuses on the radiographic diagnosis of OVF, especially where this may differ between men and women. The clinical relevance of OVF, and possible ethnic differences in OVF prevalence, are also discussed.

\section{Sex-differences in the epidemiology of osteoporotic fractures}

Before discussing OVF for which there are as yet no uniformly agreed diagnostic criteria, it may be helpful to look at those osteoporotic fractures which are definitively diagnosed. Though osteoporosis appears later in life in men than it does in women, bone loss in both sexes takes place in trabecular and cortical compartments with increased cortical porosity with age (6-9). Skeletal fragility with aging, in combination with a greater propensity to fall, results in an increased susceptibility to fractures. The most common non-vertebral osteoporotic fractures occur in distal forearm, humerus, hip, ribs and ankle. The annual incidence of fractures is higher in women than in men because at any age, there are more women than men below any given value of bone mineral density (BMD).

Hip fractures are associated with more disability, mortality and resource use than all other osteoporotic fractures combined. The epidemiology of hip fractures is well documented. In both sexes the incidence of hip fracture rises with increasing age. This increase begins at 60 to 65 years of age in women and at $\sim 75$ years of age in men $(8,11)$. The majority of hip fractures in men occur in individuals aged $>80$ years (7). In Western countries approximately three out of four hip fractures occur in women (12). This huge difference in the absolute number of fractures is partly explained by the greater life expectancy of women. The agestandardized difference between women and men is lower with a ratio of about 2:1 in most countries of the world (13).
Wrist (Colles') fractures, a common type of fragility fracture in women, are much less common in men. Of every five incident wrist fractures, four occur in women (14). In their MrOS (USA) study, Wright et al. reported that during an average of nearly 11 years $\mathrm{FU}$, the overall age-adjusted incidence of wrist fractures in the $\mathrm{MrOS}$ population was 1.60 per 1,000 person-years (15).

The age-specific fracture incidence for men and women from the Dubbo study in Australia is shown in Figure 1 (16). This population-based study documents the incidence of all symptomatic fractures from 1989 to 1992 in a predominantly Caucasian population ( $\geq 60$ years). The overall fracture incidence in women was 3,250 per 100,000 person-years and in men was 1,940 per 100,000 personyears $(1.67: 1)$. It is estimated that residual lifetime fracture risk in a person aged 60 years with average life expectancy was $29 \%$ for men and $56 \%$ for women.

To summarize, women suffer twice as many incident non-vertebral fractures as men. On average, men have hip fractures about 10-15 years later in life than women (17).

\section{Clinical significance of radiographic OVF in men}

The semi-quantitative (SQ) criteria proposed by Genant et al. are now commonly used for identifying osteoporotic vertebral deformity (VD) for vertebrae T4 to L4 $(18,19)$. According to Genant et al., a vertebra is graded based on visual inspection of the anterior, middle, or posterior heights as normal (grade-0), mildly deformed (grade-1, a $20-25 \%$ reduction in one of the three heights and a reduction in area of 10-20\%), moderately deformed (grade-2, a 25-40\% reduction in any height and a reduction in area of $20-40 \%$ ), and severely deformed (grade-3, a $40 \%$ or more reduction in height and area). In addition to the vertebral height reduction estimation, emphasis is also placed on the radiological evaluation of osteoporotic deformity. Though the initial description of the SQ method request readers to estimated height loss, calculated height loss by direct measure is commonly incorporated into practice, thus it become a mixture of qualitative and quantitative approach. Genant's SQ criteria were initially developed for epidemiology and clinical trials for elderly women; the use of these criteria in elderly men has been less validated than it has in women. Moreover, radiologists may often apply only the iconic classification of VF without reference to the radiological findings as a whole.

In terms of population statistics, radiographic OVFs in men have been documented to be relevant. There 

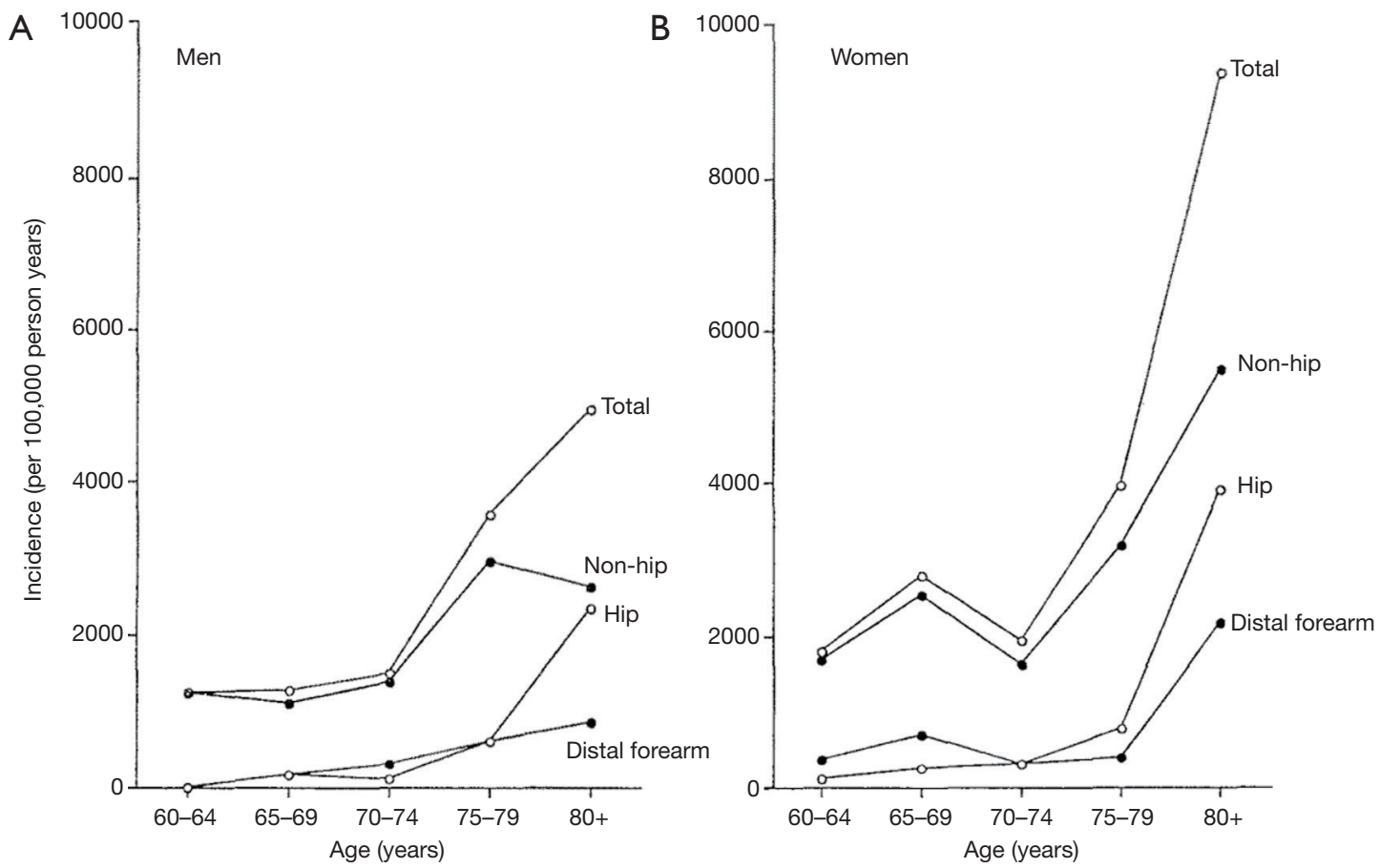

Figure 1 Age-specific fracture incidence for men (A) and women (B) in Dubbo study (Australia). There is an exponential increase in total and hip fractures for both sexes with increasing age. There is also an exponential increase in non-hip and distal forearm fractures in women but not men. [Reproduced with permission from (16)].

is a positive relationship between the severity of OVFs and the deterioration of the microstructure in trans-iliac bone biopsies: the more severe the OVFs, the lower the trabecular number and connectivity in women (20) and men $(21,22)$. Fink et al. (23) reported that, unlike in men without incident OVF, those with incident radiographic-only OVF were also significantly more likely at $\mathrm{FU}$ to report back pain and limited usual activity from back pain. Karlsson et al. (24) reported that elderly men with a prevalent OVF had an increased risk of sustaining new fractures compared with men without an OVF. Elderly men with two or more prevalent VF, different types of fractures, fractures in both the thoracic and lumbar regions, and a degree of vertebral body compression in the three worst quartiles are at an especially high risk of sustaining new fractures (24).

On the other hand, there is evidence that radiographic OVF in elderly men diagnosed according to most of the commonly used criteria (morphometric criteria, Genant's SQ criteria) generally have less clinical relevance than radiographic OVF with morphologic abnormalities in elderly women. With a modified Genant SQ method and OVF considered when a reduction in vertebral height and/ or compression of $\geq 10 \%$ of the estimated vertebral body height, Kherad et al. (25) reported that in men with one or several OVFs, there were no significant differences in the presence of back pain in any ages, nor there were differences in the presence of back pain regarding type or number of fractures. Based on vertebral morphometry applied to DXA derived images, Waterloo et al. (26) reported that presence of OVF in women was associated with an increased risk of back pain and lower quality of life score, but these associations were not present in men. In MrOS (USA) FU study (mean base-line age: 72.9 years), Ensrud et al. (27) reported $13.5 \%$ of incident SQ radiographic OVF in elderly men were also clinically diagnosed as incident fractures. In contrast, studies on elderly women suggest that one-quarter to one-third of incident radiographic OVF are also clinically diagnosed as fracture events $(27,28)$. For example, in the postmenopausal women attending the Fracture Intervention Trial Research study, Fink et al. (28) reported that about $25 \%$ of incident radiographic OVF were also diagnosed as clinical VF.

Clinical OVF are less common in elderly men than in elderly women. Cooper et al. (29) reported incidence of clinically diagnosed VF in the predominantly white population of Rochester, Minnesota, USA. In the 5-year 
study period of $1985-1989$, the age-adjusted incidence rate in women (145 per 100,000 person-years) was almost twice that in men (73 per 100,000 person-years). Freitas et al. (30) reported that, despite a large number of elderly men $(\mathrm{n}=5,995)$ followed-up for $\sim 5$ years, there were relatively few clinical VFs. They further noted that VFs in elderly men identified in community clinical settings are usually associated with falls and other low-energy trauma.

Recently Wáng et al. demonstrated that, compared with age-matched elderly Chinese women, elderly Chinese men at their early seventies have lower risk of short-term (4-year period) incident new OVF. Even for those with existing VF at baseline (BL), elderly Chinese men are associated with much lower further risk of incident new OVF as compared with elderly Chinese women (31-33).

OVF can be associated with decreases in trunk extension torque, spinal motion, functional reach, mobility skills and walking distance (34). Schlaich et al. (35) reported that pulmonary function is significantly diminished in patients with OVF as compared with chronic low back pain patients without evidence of manifest osteoporosis. Of concern are studies in women suggesting increased mortality rates in patients with OVF with a $23 \%$ to $34 \%$ increase in mortality over an 8-year period in one study (36). However, these mortality rates are in general not directly related to fracture; rather, OVF is a marker for medical frailty. In European Prospective Osteoporosis Study (EPOS) study, Ismail et al. (37) reported that for 6,480 subjects, 189 deaths (56 women and 133 men) occurred during a total of 14,380 person-years of FU (median 2.3 years). In women, after age adjustment, there was a modest excess mortality in those with, compared with those without, osteoporotic VD: rate ratio $(\mathrm{RR})=1.9$ (95\% CI: 1.0, 3.4). In men, the excess risk was smaller and non-significant with $\mathrm{RR}=1.3(95 \%$ CI: 0.9, 2.0). After further adjusting for smoking, alcohol consumption, previous hip fracture, general health, body mass index and steroid use, the excess risk was reduced and non-significant in both sexes: women, RR $=1.6$ (95\% CI: 0.9, 3.0); men, $\mathrm{RR}=1.2$ (95\% CI: 0.7, 1.8). There was a residual, though non-significant excess risk of death after adjustment for adverse health factors. Ismail et al. (37) suggested that this may be due to failure to adequately control for adverse health factors or to residual confounding. There was no evidence of a dose-response relationship between mortality and number of deformities, suggesting that the excess mortality associated with osteoporotic VD is due to adverse health factors linked with both VD and increased mortality. However, it remains possible that, in uncommon cases,
OVF may influence mortality more directly because of their association with chronic back pain, immobility and change in posture, which may increase the risk of infection and death.

\section{Radiographic diagnosis of OVF in men}

Despite years of research, the radiographic criteria for diagnosing OVF and its grading remain debated (38-44). VDs can be due to a number of causes such as osteoporotic fracture, traumatic fracture, and causes other than fracture such as osteoarthritis, or adolescent epiphysitis (Scheuermann disease). A substantial portion of radiographic OVF are asymptomatic, and because of this, the diagnosis of radiographic OVF is difficult. This is different from, for example, the case of diagnosis of malignant tumors, where a biopsy, a FU of a couple of months, or surgical pathology, usually establish the conclusive diagnosis. For OVF, biopsy is usually not obtained, and even years of FU may not necessarily provide the conclusive diagnosis.

For both men and women's results, VD's shapes are commonly classified into (I) biconcave (II) wedged, (III) both biconcave and wedged, (IV) crush. Whether wedged VD reflects OVF is a matter of dispute. Based on morphometrical evaluation for EPOS subjects, Lunt et al. (45) noted that VDs in which the mid-height loss only, or mid and anterior heights loss were both reduced, and crush deformities were associated with reduced BMD; and those VDs were significantly more prevalent in women than in men. However, VDs involving loss of anterior vertebral body height alone, which represent $21 \%$ of deformities in women and $29 \%$ of deformities in men, were poorly correlated with low BMD. With EPOS subjects, for a mean FU of 3.8 years, Lunt et al. (46) reported relative OVF risk during $\mathrm{FU}$ differ according to the shape of the prevalent $\mathrm{VD}$, ranging from 5.9 (95\% CI: 4.1, 8.6) if the anterior and mid heights were reduced, $3.3(2.3,4.8)$ if the mid height was reduced, and $1.9(1.0,3.4)$ if the anterior height was reduced. They also described the most common type of deformity as biconcavity (46).

Hence, for wedge-shaped VDs (or VD with anterior height reduction only), a diagnose of OVF may be questionable if rarely valid. It is possible that wedged OVF may indeed occur, particularly when these VDs are associated with some degree of external low energy trauma. Trabecular density is lower in the anterior versus posterior regions of the vertebral centrum (47). With difference which increases with degeneration of the adjacent 
intervertebral disc and with aging, the vertebra integrity is less resistant to anterior flexion force than axial compression force $(48,49)$. Disc degeneration may have an important influence on VF etiology, with disc material properties may influence vertebral strength (50). In an ex-vivo specimen study, Jackman et al. (51) noted that under the combined loading of axial compression combined with anterior flexion, deflection initiated and remained the largest at the anterior central endplate or the anterior ring apophysis, depending in part on health of the adjacent intervertebral disc. This deflection was accompanied by outward bulging of the anterior cortex. With an ex-vivo study, Adams et al. (48) noted that intervertebral disc degeneration is associated with locally reduced BMD of the anterior vertebral body and inferior trabecular architecture. Vertebrae specimens from elderly subjects shows the anterior third of the vertebral body had lower trabecular volume fraction, fewer trabeculae, and greater intertrabecular spacing compared with the posterior third (48). These predispose to anterior fracture when the spine is flexed. Flexed postures concentrates loading on the weakened anterior vertebral body, leading to compressive failure at reduced load.

Leidig-Bruckner et al. (52) applied an algorithm for radiological differential classification (RDC), and their RDC's reading were compared with BMD measurement as well as Eastell and McCloskey's morphometric criteria $(53,54)$. They noted the agreement between RDC and morphometric methods was poor, and more so for elderly men than for elderly women. In men, $62-86 \%$ of cases with morphometric VD were classified by RDC as nonosteoporotic, compared with $31-68 \%$ in women, with most of these VDs had wedge deformities of the thoracic spine. On the other hand, up to $80 \%$ of OVFs in men and up to $48 \%$ in women were missed by morphometry, in particular endplate fractures at the lumbar spine. Although VDs by most definitions were significantly and inversely related to BMD in both sexes, a much stronger association existed between BMD and osteoporotic fractures defined by RDC. Leidig-Bruckner et al. (52) concluded that assessment of vertebral osteoporotic fracture by quantitative methods alone will result in considerable misclassification, especially in men. Leidig-Bruckner et al. also suggested the criteria derived from women is likely to be unsuitable for men.

The diagnosis of OVF among VDs is difficult and even more so in men than in women for a number of reasons. Duan et al. (55) suggested that VF risk is the same in young women and men but, during aging, subperiosteal bone formation increases vertebral cross-sectional area more in men than in women and volumetric BMD decreased less in men than in women. Thus, VF risk does not generally increase in elderly men as much as in elderly women; though in the smaller subgroups of elderly men with osteoporosis, the VF risk may be only slightly less than the elderly women with osteoporosis (56). The vertebrae of men may be physiologically more wedge-shaped than those of women $(57,58)$. Men are more likely to have high energy trauma than women across the whole life span. Differentiation of OVF from VD due to old traumatic cause may not be easy (59). There is a high likelihood that OVF has been over-reported in previous epidemiological studies and even more so in men, an issue discussed by Szulc et al. (60). Ismail et al. (61) described that risk factors for men with multiple VDs are consistent with those well known for osteoporotic women. However, this is not true for men with single/dual deformities where the correlation with low BMD was poorer. There was a marked increase in the prevalence of multiple VDs with increasing age, but only a modest effect of age on the prevalence of single deformities (61), suggesting a portion of the VDs might not be osteoporotic. Similar observations have been made in a report from the Canadian Multicentre Osteoporosis Study (62). To address this problem, based on BMD characteristics, Szulc et al. (60) recommended a cutoff of $25 \%$ for wedge deformities from T6 to T9, and they further commented that a cutoff of $30 \%$ for wedge deformities from T6 to T9 and of $25 \%$ for other deformities has a high specificity and a moderate sensitivity for identifying VDs related to low BMD in men, while SQ grade-1 deformities are often deformities related to non-osteoporotic disease of the spine. One study showed, comparing Genant's SQ criteria, Szulc et al.'s criteria demonstrated better association between existing osteoporotic VD at BL and further incident new OVF at year-4 FU (32).

Recent reports emphasize the importance of identifying osteoporotic endplate and/or cortex fractures (ECF) [also called algorithm-based qualitative (ABQ) fracture, osteoporotic endplate depression and anterior cortex buckling] $(31,33,41,56,63-68)$. It has been shown that mild VDs identified by $A B Q$, but not by $S Q$, were associated with lower BMD $(56,68)$. Lentle et al. (67) showed ECF positive grade-1 VF was associated with higher risk of VFs as well as non-vertebral major osteoporotic fracture, while grade-1 SQ-VD was not associated with nonvertebral fracture risk. In MrOS \& MsOS (Hong Kong) BL studies (56), it was demonstrated that while the overall Genant SQ criteria based VD prevalence is only slightly lower in men 
than women (i.e., $13.2 \%$ vs. $16.1 \%$ ), ECF is substantially lower in men than women (i.e., $5.88 \%$ vs. $11.93 \%$ ). Moreover, $63.2 \%$ of the VDs in men were grade- 1 , while only $30.5 \%$ of the VDs in women were grade- 1 (56). VFs in men with $25-34 \%$ height loss rarely simultaneously demonstrate ECF, while it is common for VF in women with $25-34 \%$ height loss to be associated with ECF (69). Recently Wáng et al. (31) showed, in elderly women, within the same mild/moderate SQ grades, compared with the subjects without ECF, the subjects with ECF are associated with a higher short-term future risk of new incident OVF.

Particular care is important in diagnosing OVF at midthoracic level, as this is where false positive diagnoses more likely are made. There is a high possibility that OVF at midthoracic level (T7-T9) have been over-diagnosed in many cases $(52,70)$. Wedging from remodeling in osteoarthritis may be confused with wedging due to osteoporotic fracture (71). Abdel-Hamid Osman et al. (71) noted that while osteoporotic fracture of the thoracic spine is characterized by an exaggerated reduction of the mid-height to posterior height in addition to reduction of the anterior to posterior height. In the osteoarthritic wedging, the anterior/posterior height ratio is lower than the mid/posterior height ratio. In osteoarthritis, reduction in anterior height of the vertebral body is the consequence of remodeling, likely a silent adaptation over years of hyper-lordosis.

Taken together from the above discussions, it is likely that OVF may have been over-diagnosed in many epidemiological studies of men, particularly diagnosing wedge-shaped VDs as OVF requires great caution. A more stringent criterion for definition of OVF for epidemiological studies in men is needed. Cawthon at al. (72) used the criteria that, unless there is evidential ECF for SQ grade-1 deformity, VF should be considered only when $\geq$ grade- 2 deformity exists. Even so, we expect there is a possibility that some ECF negative grade-2 deformities may not be true fracture. Thus, another possibility will be that only ECF positive osteoporotic VD and osteoporotic VD with $\geq 1 / 3$ vertebral height loss are considered OVF (69). For men, the criteria of Szulc et al. (60) may also be considered. However, convertible criteria between men and women will facilitate comparative studies. As noted above, before suggesting a VF to be osteoporotic, in addition to considering the possibility of physiological wedging, degenerative wedging and other causes, secondary causes such as old trauma, metabolic diseases, and oncologic conditions, should be excluded.

However, apart from epidemiological studies and clinical trials, for clinical patients seen with back pain we emphasize the importance of identifying VDs with less than $20 \%$ vertebral body height loss $(41,64,73-75)$. In cases of ambiguity and if clinical decision-making hinges on the diagnosis of a fracture, then comparison with previous images, a radionuclide scan, computed tomography (with sagittal reformation), and/or MRI may provide clearer evidence (65). To depict the bone marrow edema at acute stage VF, MRI fat suppression on T2-weighted images (commonly STIR sequence) is essential. Chronic vertebral compression fractures are characterized by morphologic changes but normal signal apropos of the bone marrow.

\section{Comparative prevalence of radiographic OVF in elderly men and women}

Because there is no universally accepted definition of OVF, and a substantial proportion of OVF do not come to medical attention, the epidemiology of VFs is less well understood than that of hip fractures. The risk for osteoporotic fracture increases greatly in elderly men after age of 80 years $(30,76)$ (Figure 2). For epidemiological studies of OVF, it may not be meaningful to study OVF in men younger than 60 years. Some previous publications on OVF for men may have included subjects of too young age.

For MsOS (Hong Kong) and MrOS (Hong Kong) studies, men and women of similar age and from the same community-based population were investigated using the same methodology, thereby enabling direct comparison of the results in men and women. MsOS (Hong Kong) and MrOS (Hong Kong)'s data iterate that there is a high proportion of SQ grade-1 VD in men which may not be true OVF (Table 1). If only accepting vertebrae with ECF, the VF prevalence in men is about half of that of women $(49.3 \%)$. By accounting those with grade-2/3 VD and grade-1 VD co-existing with ECF, the VF prevalence in men is slightly less half of that in women (41\%, Table 1) (56). Based on morphometrical assessment, Lunt et al. (46) estimated a total OVF incidence of 5.9 fractures per 1,000 person/years in men (95\% CI: 4.6, 7.4) and 10.1 OVF per 1,000 person/years in women (95\% CI: 8.5, 11.9). This male-female ratio is very similar to other clinical fracture of such as hip $(9,12-16)$. Figure 3 from MsOS (Hong Kong) and MrOS (Hong Kong) studies shows while male-female ratios are the same for the three age groups, with the prevalence of male grade-2/3 VF and ECF being approximately half of the women, the absolute difference in VF prevalence between men and women actually increase over age (Figure $3 A$ ). OVF's vertebral level distribution is 


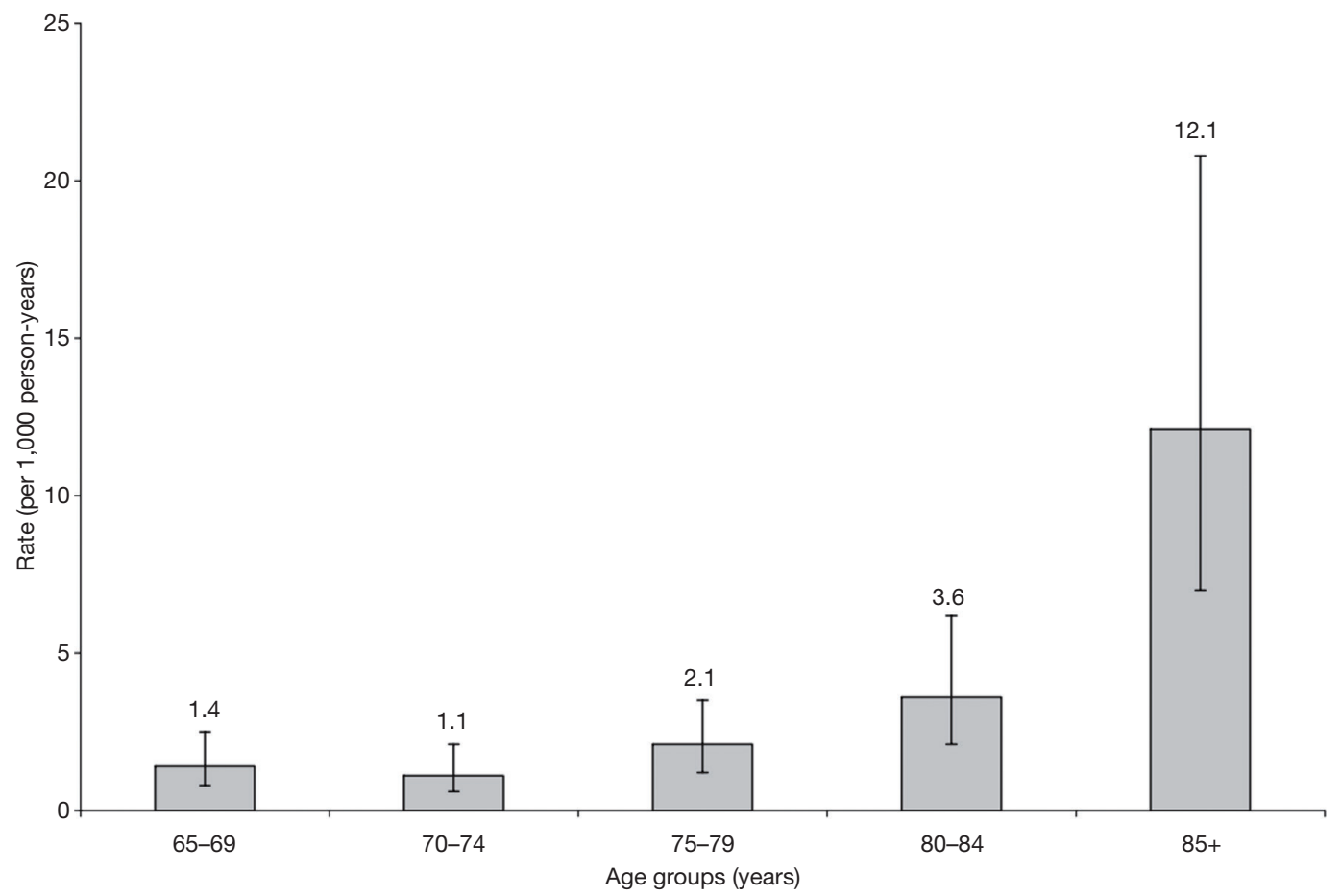

Figure 2 Clinical VFs rates (per 1,000 person-years) and 95\% confidence intervals by 5-year age categories in the MrOS (USA) Study. The mean FU was 4.7 years. [Reproduced with permission from (30)]. VF, vertebral fracture; FU, follow-up.

Table 1 Comparison of Genant's VD vs. ECF in assessing spine OVF in MrOS (Hong Kong) and MsOS (Hong Kong) studies

\begin{tabular}{|c|c|c|c|c|c|c|}
\hline Grade & \multicolumn{2}{|c|}{ Men $(n=1,954)$} & \multicolumn{2}{|c|}{ Women $(n=1,953)$} & \multicolumn{2}{|c|}{$P$ value of chi-square } \\
\hline Grade- $0, \%$ & 86.80 & 94.12 & 83.92 & 88.07 & & \\
\hline Grade-1, \% & 8.34 & 1.89 & 5.07 & 3.33 & 0.0004 & 0.0022 \\
\hline Grade-2, \% & 2.61 & 1.74 & 5.12 & 3.07 & $<0.0001$ & 0.0030 \\
\hline Total (Grade 1-3), \% & 13.20 & 5.88 & 16.08 & 11.93 & 0.0111 & $<0.0001$ \\
\hline
\end{tabular}

Grade 1, 2, 3 indicate prevalence of deformity/fracture in each grade. VD, vertebral deformity; ECF, endplate and/or cortex fracture; OVF, osteoporotic vertebral fracture. [Reproduced with permission from (56)].

similar between men and women (56).

However, for men with osteoporosis (based on hip BMD measurement), MsOS (Hong Kong) and MrOS (Hong Kong)'s results show OVF prevalence is similar between men and women (though still slightly lower in men) (Figure 3B). Schuit et al. (77) also reported that men and women $\geq 55$ years of age participating in the Rotterdam Study had similar associations between BMD and risk of hip and other nonvertebral fractures. Nguyen et al. (78) found similar patterns of BMD and fracture risk in men and women. Johnell et al. (79) also reported in a metaanalysis that low BMD is a risk factor for fracture of substantial importance and is similar in both sexes. At the age of 65 years, hip fracture risk ratio increased by 2.94 (95\% CI: $2.02,4.27)$ in men and by 2.88 (95\% CI: 2.31 , 3.59 ) in women for each standard deviation (SD) decrease in BMD. At the age of 65 years, the risk of osteoporotic fractures increased in men by 1.41 per SD decrease in BMD $(95 \%$ CI: $1.33,1.51)$ and in women by 1.38 per SD (95\% CI: 1.28, 1.48). Cummings et al. (80) suggested the 

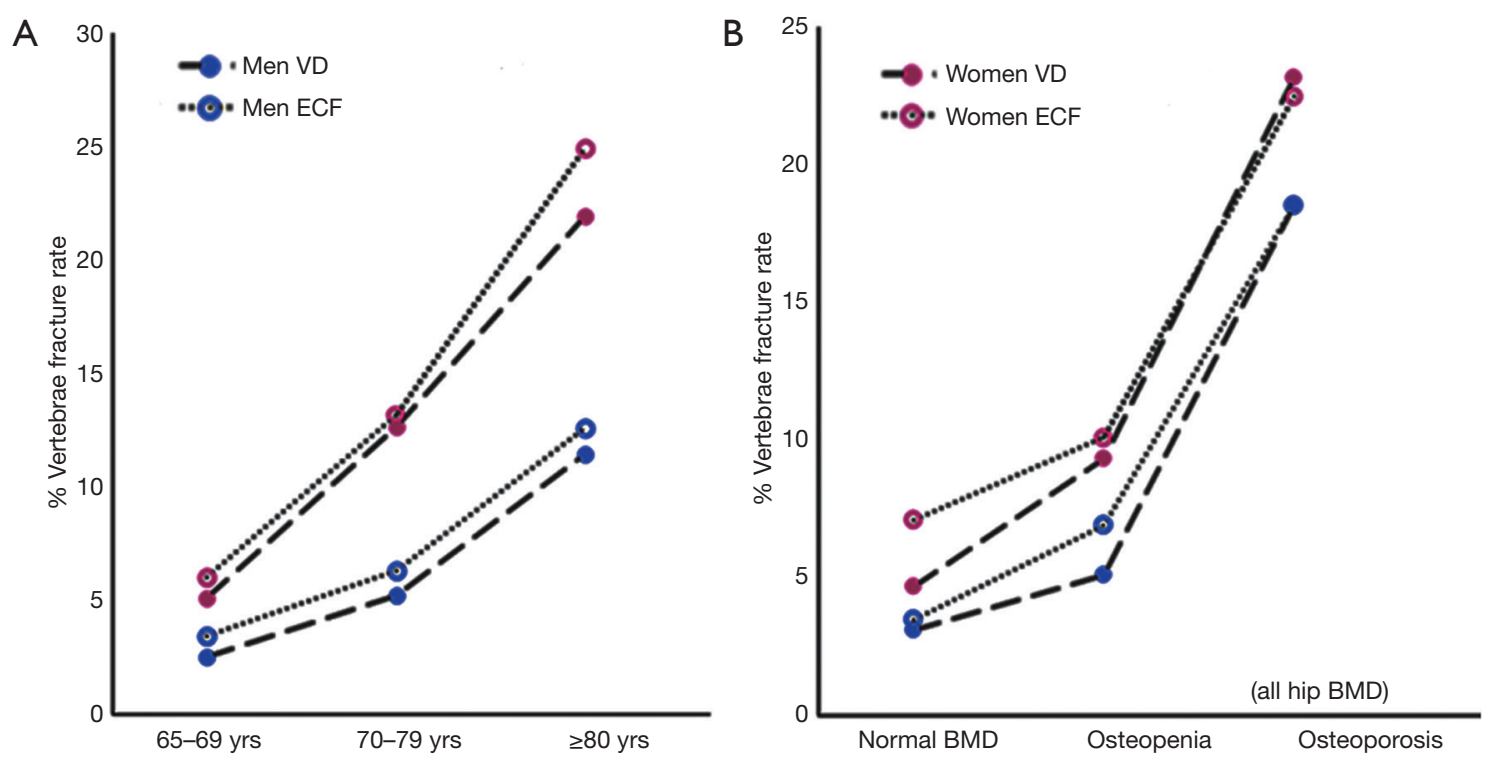

Figure 3 Prevalence of OVF among three age groups of Hong Kong Chinese men and women (65-69, 70-79, and $\geq 80$ years) (A), and among normal BMD, osteopenia and osteoporosis subjects (B). Genant's VD included deformities grade-2 and 3 only as grade-1 may not be true fracture; ECF included fracture grade-1, 2 and 3. Blue circles for men and red circles for female. [Reproduced with permission from (56)]. OVF, osteoporotic vertebral fracture; BMD, bone mineral density; VD, vertebral deformity; ECF, endplate and/or cortex fracture

relationship between hip BMD and hip fracture risk was no less strong in men than that of women, with each SD decrease in hip BMD increased the risk of hip fracture 3.2fold. Shin et al. (81) reported that despite large differences in the prevalence of fracture and in the characteristics of the men, the associations between BMD and fracture status were remarkably similar across differential ethic/race groups.

\section{Ethnic differences in radiographic OVF prevalence}

Ethic differences for BMD and clinical fragility fractures have been documented. It has been noted that spine and hip BMD are relatively high in men of African origin, and relatively low in East Asian men (Chinese, Korean, and Japanese) $(81,82)$. Clinical fragility fractures tend to be more prevalent among elderly Caucasian men, while relatively less prevalent among elderly East Asian men (82-84). African descendants may have even lower prevalence of clinical fragility fractures (84). The lower BMD observed among men of Asian descent compared with Caucasian men can be largely explained by differences in body size (82). Rates of BMD loss with aging appear to be similar between Caucasian and African Americans but slower in Asian men (85). The association between BMD and fracture risk appears to be similar across race and ethnic groups (81).

Direct comparison with prevalence and incident VFs among different studies is difficult because of the differences in study methodologies, which include the differences in BL age as well as the VD/VF definitions. Kwok et al. reported that the age-specific OVF prevalence of elderly Chinese women in Hong Kong (mostly southern Chinese) is very similar to that of women in Beijing (mostly northern Chinese), and to that of Japanese women and Korean women, while lower than elderly Caucasian women (estimated to be 30\% lower) (86). Other aspects of spine degeneration also tend to be slightly more severe in elderly Caucasian subjects than in East Asians. It was shown that Caucasian Americans have a higher degenerative spondylolisthesis prevalence, being approximately $60-70 \%$ higher than that of elderly Chinese $(87,88)$.

The same with the OVF prevalence ratio of Chinese women vs. Caucasian women (86), elderly Chinese men's OVF prevalence is likely to some extent lower than that of elderly Caucasian men. The European Vertebral Osteoporosis Study (EVOS) reported that approximately $20 \%$ of men aged 50 to 79 years had at least one OVF (Eastell method with 3 SD criteria) (89). Using morphometry applied to DXA images, Waterloo et al. reported at least one OVF is present in $14 \%$ of men 
aged $>50$ years in Norway (26). With a more comparable methodology to MrOS (Hong Kong) study, the MrOs (Sweden) study $(24,25)$ shows all-inclusive SQ OVF prevalence of $15.1 \%$ (SQ threshold of $>10 \%$ vertebral height loss) as compared with all-inclusive SQ VF prevalence of $13.2 \%$ (SQ threshold of $>20 \%$ vertebral height loss) in MrOS (Hong Kong) results. In Van der Klift et al.'s Rotterdam study (mean age at baseline BL: $65.4 \pm 6.6$ years, $\mathrm{FU}$ period 6.3 years) (90), for those with $\mathrm{BL}$ normal spine, the osteoporotic VD/VF incident rate was $2.8 \%$ for men (5.2\% for women), as compared to $2.05 \%$ $(25 / 1,219)$ in MrOS (Hong Kong) study (mean age at BL: 71.7 years, range $65-91$ years, $\mathrm{FU}$ period 4 years). In the EPOS study (91) (mean age at BL: $63.3 \pm 7.9$ years, mean FU period of 3.8 years, an incident morphometric VF was a $20 \%(+4 \mathrm{~mm})$ or more reduction in anterior, middle, or posterior vertebral height-plus satisfying criteria for VD using the McCloskey-Kanis method in the FU radiograph), the osteoporotic VD/VF incidence was 4.5/1,000 personyears in men $(9.3 / 1,000$ person-years in women), as compared to 5.33/1,000 person-years MrOS (Hong Kong) study (criteria: for progression of a BL VD, a further height decrease of $\geq 15 \%$ was a VD progression; a new incident VD was a qualitative VD which could be either a change from grade- 0 at $\mathrm{BL}$ to grade- $2 / 3 \mathrm{VD}$ at $\mathrm{FU}$, or a change from grade- 0 to grade- $1 \mathrm{VD}$ with $\geq 10 \%$ height loss during the FU period) (32). In MrOS (USA) study, Fink et al. reported that, of 5,994 men followed-up for an average of 4.7 years, $4.65 \%$ had incident radiographic VFs (SQ methods: a distinct alteration in morphology of vertebral body resulting in a higher grade (grade 1-3) when compared to BL radiograph) (23). In MrOS (Hong Kong) study, for 38 cases who had SQ grade-3 OVF, only two cases had new OVF or OVF progression (including one new OVF at L5) at year-4 $\mathrm{FU}(32,33)$.

In conclusion, for epidemical studies and clinical trials we suggest that OVF criteria for women may not be directly applicable for men. Before better evidence is available, ECF sign positive Genant SQ grade-1, as well as GSQ grade-2/3 VDs can be accepted as valid for prevalent OVF. Another possibility will be that only ECF positive osteoporotic VD and osteoporotic VD with $\geq 1 / 3$ vertebral height loss are considered OVF. The OVF prevalence for men is expected to be approximately half (or even slightly less than half) of prevalence for age-matched women. Even so, the clinical relevance for elderly men with OVF may be less than that of elderly women. For elderly men with hip BMD based osteoporosis, the OVF risk is as high as that for osteoporotic women. Chinese elderly men have lower OVF prevalence than age-matched Caucasian men. For wedge-shaped VDs or VDs with anterior height reduction only, to diagnose them as OVF requires caution. Particular attention should be paid to the mid-thoracic level as this is where over-diagnosis commonly occurs. If clinical decision-making hinges on the diagnosis of a fracture, then comparison with previous images, a radionuclide scan, computed tomography (with sagittal reformation), MRI, and/or careful FU is recommended.

\section{Acknowledgments}

Funding: None.

\section{Footnote}

Conflicts of Interest: Both authors have completed the ICMJE uniform disclosure form (available at http://dx.doi. org/10.21037/qims-2020-21). YXJW served as the unpaid Editor-In-Chief of Quantitative Imaging in Medicine and Surgery. The other author has no conflicts of interest to declare.

Open Access Statement: This is an Open Access article distributed in accordance with the Creative Commons Attribution-NonCommercial-NoDerivs 4.0 International License (CC BY-NC-ND 4.0), which permits the noncommercial replication and distribution of the article with the strict proviso that no changes or edits are made and the original work is properly cited (including links to both the formal publication through the relevant DOI and the license). See: https://creativecommons.org/licenses/by-nc-nd/4.0/.

\section{References}

1. Klotzbuecher CM, Ross PD, Landsman PB, Abbott TA 3rd, Berger M. Patients with prior fractures have an increased risk of future fractures: a summary of the literature and statistical synthesis. J Bone Miner Res 2000;15:721-39.

2. Black DM, Cummings SR, Karpf DB, Cauley JA, Thompson DE, Nevitt MC, Bauer DC, Genant HK, Haskell WL, Marcus R, Ott SM, Torner JC, Quandt SA, Reiss TF, Ensrud KE. Randomised trial of effect of alendronate on risk of fracture in women with existing vertebral fractures. Fracture Intervention Trial Research Group. Lancet 1996;348:1535-41. 
3. Wells GA, Cranney A, Peterson J, Boucher M, Shea B, Robinson V, Coyle D, Tugwell P. Etidronate for the primary and secondary prevention of osteoporotic fractures in postmenopausal women. Cochrane Database Syst Rev 2008;(1):CD003376.

4. Wells GA, Cranney A, Peterson J, Boucher M, Shea B, Robinson V, Coyle D, Tugwell P. Alendronate for the primary and secondary prevention of osteoporotic fractures in postmenopausal women. Cochrane Database Syst Rev 2008;(1):CD001155.

5. Harvey NCW, McCloskey EV, Mitchell PJ, DawsonHughes B, Pierroz DD, Reginster JY, Rizzoli R, Cooper C, Kanis JA. Mind the (treatment) gap: a global perspective on current and future strategies for prevention of fragility fractures. Osteoporos Int 2017;28:1507-29.

6. Seeman E, Bianchi G, Khosla S, Kanis JA, Orwoll E. Bone fragility in men--where are we? Osteoporos Int 2006;17:1577-83.

7. Cauley JA. Osteoporosis in men: prevalence and investigation. Clin Cornerstone 2006;8 Suppl 3:S20-5.

8. Khosla S, Amin S, Orwoll E. Osteoporosis in men. Endocr Rev 2008;29: 441-64.

9. Gennari L, Bilezikian JP. Osteoporosis in men. Endocrinol Metab Clin North Am 2007;36:399-419.

10. Ensrud KE, Blackwell TL, Cawthon PM, Bauer DC, Fink HA, Schousboe JT, Black DM, Orwoll ES, Kado DM, Cauley JA, Mackey DC; Osteoporotic Fractures in Men (MrOS) Study of Osteoporotic Fractures (SOF) Research Groups. Degree of trauma differs for major osteoporotic fracture events in older men versus older women. J Bone Miner Res 2016;31:204-7.

11. Ahmed LA, Schirmer H, Bjørnerem A, Emaus N, Jørgensen L, Størmer J, Joakimsen RM. The gender- and age-specific 10-year and lifetime absolute fracture risk in Tromsø, Norway. Eur J Epidemiol 2009;24:441-8.

12. Burge R, Dawson-Hughes B, Solomon DH, Wong JB, King A, Tosteson A. Incidence and economic burden of osteoporosis-related fractures in the United States, 20052025. J Bone Miner Res 2007;22:465-75.

13. Rapp K, Büchele G, Dreinhöfer K, Bücking B, Becker C, Benzinger P. Epidemiology of hip fractures: Systematic literature review of German data and an overview of the international literature. Z Gerontol Geriatr 2019;52:10-6.

14. Ensrud KE. Epidemiology of fracture risk with advancing age. J Gerontol A Biol Sci Med Sci 2013;68:1236-42.

15. Wright NC, Hooker ER, Nielson CM, Ensrud KE, Harrison SL, Orwoll ES, Barrett-Connor E; Osteoporotic Fractures in Men (MrOS) Study Research Group.
The epidemiology of wrist fractures in older men: the Osteoporotic Fractures in Men (MrOS) study. Osteoporos Int 2018;29:859-70.

16. Jones G, Nguyen T, Sambrook PN, Kelly PJ, Gilbert C, Eisman JA. Symptomatic fracture incidence in elderly men and women: the Dubbo Osteoporosis Epidemiology Study (DOES). Osteoporos Int 1994;4:277-82.

17. Nabipour I, Ebeling PR, Seibel MJ. Osteoporosis in older men. Expert Review of Endocrinology \& Metabolism 2011;6:629-45.

18. Genant HK, Wu CY, van Kuijk C, Nevitt MC. Vertebral fracture assessment using a semiquantitative technique. J Bone Miner Res 1993;8:1137-48.

19. Genant HK, Jergas M. Assessment of prevalent and incident vertebral fractures in osteoporosis research. Osteoporos Int 2003;14 Suppl 3:S43-55.

20. Genant HK, Delmas PD, Chen P, Jiang Y, Eriksen EF, Dalsky GP, Marcus R, San Martin J. Severity of vertebral fracture reflects deterioration of bone microarchitecture. Osteoporos Int 2007;18:69-76.

21. Legrand E, Chappard D, Pascaretti, Duquenne M, Krebs S, Rohmer V, Basle MF, Audran M. Trabecular bone microarchitecture, bone mineral density, and vertebral fractures in male osteoporosis. J Bone Miner Res 2000;15:13-9.

22. Ostertag A, Cohen-Solal M, Audran M, Legrand E, Marty C, Chappard D, de Vernejoul MC. Vertebral fractures are associated with increased cortical porosity in iliac crest bone biopsy of men with idiopathic osteoporosis. Bone 2009;44:413-7.

23. Fink HA, Litwack-Harrison S, Ensrud KE, Shen J, Schousboe JT, Cawthon PM, Cauley JA, Lane NE, Taylor BC, Barrett-Connor E, Kado DM, Cummings SR, Marshall LM; Osteoporotic Fractures in Men (MrOS) Study Group. Association of incident, clinically undiagnosed radiographic vertebral fractures with followup back pain symptoms in older men: the Osteoporotic Fractures in Men (MrOS) study. J Bone Miner Res 2017;32:2263-8.

24. Karlsson MK, Kherad M, Hasserius R, Nilsson JÅ, Redlund-Johnell I, Ohlsson C, Lorentzon M, Mellström D, Rosengren BE. Characteristics of prevalent vertebral fractures predict new fractures in elderly men. J Bone Joint Surg Am 2016;98:379-85.

25. Kherad M, Rosengren BE, Hasserius R, Nilsson JÅ, Redlund-Johnell I, Ohlsson C, Lorentzon M, Mellström D, Karlsson MK. Low clinical relevance of a prevalent vertebral fracture in elderly men--the MrOs Sweden study. 
Spine J 2015;15:281-9.

26. Waterloo S, Søgaard AJ, Ahmed LA, Damsgård E, Morseth B, Emaus N. Vertebral fractures and self-perceived health in elderly women and men in a population-based crosssectional study: the Tromsø Study 2007-08. BMC Geriatr 2013;13:102

27. Ensrud KE, Blackwell TL, Fink HA, Zhang J, Cauley JA, Cawthon PM, Black DM, Bauer DC, Curtis JR, Orwoll ES, Barrett-Connor E, Kado DM, Marshall LM, Shikany JM, Schousboe JT; Osteoporotic Fractures in Men (MrOS) Research Group. What proportion of incident radiographic vertebral fractures in older men is clinically diagnosed and vice versa: a prospective study. J Bone Miner Res 2016;31:1500-3.

28. Fink HA, Milavetz DL, Palermo L, Nevitt MC, Cauley JA, Genant HK, Black DM, Ensrud KE; Fracture Intervention Trial Research Group. What proportion of incident radiographic vertebral deformities is clinically diagnosed and vice versa? J Bone Miner Res 2005;20:1216-22.

29. Cooper C, Atkinson EJ, O'Fallon WM, Melton LJ III. Incidence of clinically diagnosed vertebral fractures: a population-based study in Rochester, Minnesota, 19851989. J Bone Miner Res 1992;7:221-7.

30. Freitas SS, Barrett-Connor E, Ensrud KE, Fink HA, Bauer DC, Cawthon PM, Lambert LC, Orwoll ES; Osteoporotic Fractures in Men (MrOS) Research Group. Rate and circumstances of clinical vertebral fractures in older men. Osteoporos Int 2008;19:615-23.

31. Wáng YX, Che-Nordin N, Deng M, Leung JCS, Kwok AWL, He LC, Griffith JF, Kwok TCY, Leung PC. Osteoporotic vertebral deformity with endplate/cortex fracture is associated with higher further vertebral fracture risk: the Ms. OS (Hong Kong) study results. Osteoporos Int 2019;30:897-905.

32. Wáng YX, Che-Nordin N, Deng M, Griffith JF, Leung JCS, Kwok AWL, Leung PC, Kwok TCY. Elderly males with or without existing osteoporotic vertebral fracture have much lower future vertebral fracture risk than elderly females: the MrOS (Hong Kong) year-4 follow-up spine radiograph study. Osteoporos Int 2019;30:2505-14.

33. Wáng YX, Che-Nordin N, Leung JCS, Kwok TCY. Existing severe osteoporotic vertebral fractures in elderly Chinese males were only weakly associated with higher further vertebral fracture risk at year-4 follow-up. Osteoporos Int 2020. [Epub ahead of print]. doi: 10.1007/ s00198-020-05480-3.

34. Lyles KW, Gold DT, Shipp KM, Pieper CF, Martinez S, Mulhausen PL. Association of osteoporotic vertebral compression fractures with impaired functional status. Am J Med 1993;94:595-601.

35. Schlaich C, Minne HW, Bruckner T, Wagner G, Gebest HJ, Grunze M, Ziegler R, Leidig-Bruckner G. Reduced pulmonary function in patients with spinal osteoporotic fractures. Osteoporos Int 1998;8:261-7.

36. Kado DM, Browner WS, Palermo L, Nevitt MC, Genant HK, Cummings SR. Vertebral fractures and mortality in older women: a prospective study. Arch Intern Med 1999;159:1215-20.

37. Ismail AA, O'Neill TW, Cooper C, Finn JD, Bhalla AK, Cannata JB, Delmas P, Falch JA, Felsch B, Hoszowski K, Johnell O, Diaz-Lopez JB, Lopez Vaz A, Marchand F, Raspe H, Reid DM, Todd C, Weber K, Woolf A, Reeve J, Silman AJ. Mortality associated with vertebral deformity in men and women: results from the European Prospective Osteoporosis Study (EPOS). Osteoporos Int 1998;8:291-7.

38. Lentle B, Koromani F, Brown J, Oei L, Ward L, Goltzman D, Rivadeneira F, Leslie WD, Probyn L, Prior J, Hammond I, Cheung AM, Oei EH; Vertebral Fracture Research Groups of the CaMos, STOPP, and Rotterdam Studies. The Radiology of Osteoporotic Vertebral Fractures Revisited. J Bone Miner Res 2019;34:409-18.

39. Fechtenbaum J, Briot K, Paternotte S, Audran M, Breuil V, Cortet B, Debiais F, Grados F, Guggenbuhl P, Laroche M, Legrand E, Lespessailles E, Marcelli C, Orcel P, Szulc P, Thomas T, Kolta S, Roux C; bone section of the French Rheumatology Society. Difficulties in the diagnosis of vertebral fracture in men: agreement between doctors. Joint Bone Spine 2014;81:169-74.

40. Wáng YX, Che-Nordin N. Informed communication with study subjects of radiographically detected osteoporotic vertebral deformity. Quant Imaging Med Surg 2018;8:876-80.

41. Yoshida T, Nanba H, Mimatsu K, Kasai T. Treatment of osteoporotic spinal compression fractures. Conservative therapy and its limitation. Clin Calcium 2000;10:53-8.

42. Szulc P. Vertebral fracture: diagnostic difficulties of a major medical problem. J Bone Miner Res 2018;33:553-9.

43. Lentle BC. Gender and the recognition of vertebral fractures. Quant Imaging Med Surg 2020;10:1401-7.

44. Wáng YXJ, Diacinti D, Yu W, Cheng XG, NogueiraBarbosa MH, Che-Nordin N, Guglielmi G, Ruiz Santiago F. Semi-quantitative grading and extended semiquantitative grading for osteoporotic vertebral deformity: a radiographic image database for education and calibration. Ann Transl Med 2020;8:398.

45. Lunt M, Felsenberg D, Reeve J, Benevolenskaya L, 
Cannata J, Dequeker J, Dodenhof C, Falch JA, Masaryk P, Pols HA, Poor G, Reid DM, Scheidt-Nave C, Weber K, Varlow J, Kanis JA, O'Neill TW, Silman AJ. Bone density variation and its effects on risk of vertebral deformity in men and women studied in thirteen European centers: the EVOS Study. J Bone Miner Res 1997;12:1883-94.

46. Lunt M, O'Neill TW, Felsenberg D, Reeve J, Kanis JA, Cooper C, Silman AJ; European Prospective Osteoporosis Study Group. Characteristics of a prevalent vertebral deformity predict subsequent vertebral fracture: results from the European Prospective Osteoporosis Study (EPOS). Bone 2003;33:505-13.

47. Oda K, Shibayama Y, Abe M, Onomura T. Morphogenesis of vertebral deformities in involutional osteoporosis. Agerelated, three-dimensional trabecular structure. Spine (Phila Pa 1976) 1998;23:1050-5, discussion 1056.

48. Adams MA, Pollintine P, Tobias JH, Wakley GK, Dolan P. Intervertebral disc degeneration can predispose to anterior vertebral fractures in the thoracolumbar spine. J Bone Miner Res 2006;21:1409-16.

49. Matsumoto T, Ohnishi I, Bessho M, Imai K, Ohashi S, Nakamura K. Prediction of vertebral strength under loading conditions occurring in activities of daily living using a computed tomography-based nonlinear finite element method. Spine (Phila Pa 1976) 2009;34:1464-9.

50. Fields AJ, Lee GL, Keaveny TM. Mechanisms of initial endplate failure in the human vertebral body. J Biomech 2010;43:3126-31.

51. Jackman TM, Hussein AI, Curtiss C, Fein PM, Camp A, De Barros L, Morgan EF. Quantitative, 3D visualization of the initiation and progression of vertebral fractures under compression and anterior flexion. J Bone Miner Res 2016;31:777-88.

52. Leidig-Bruckner G, Limberg B, Felsenberg D, Bruckner T, Holder S, Kather A, Miksch J, Wüster C, Ziegler R, Scheidt-Nave C. Sex difference in the validity of vertebral deformities as an index of prevalent vertebral osteoporotic fractures: a population survey of older men and women. Osteoporos Int 2000;11:102-19.

53. Eastell R, Cedel SL, Wahner HW, Riggs BL, Melton LJ 3rd.Classification of vertebral fractures. J Bone Miner Res 1991;6:207-15.

54. McCloskey EV, Spector TD, Eyres KS, Fern ED, O'Rourke N, Vasikaran S, Kanis JA. The assessment of vertebral deformity: a method for use in population studies and clinical trials. Osteoporos Int 1993;3:138-47.

55. Duan Y, Seeman E, Turner CH. The biomechanical basis of vertebral body fragility in men and women. J Bone
Miner Res 2001;16:2276-83.

56. Deng M, Zeng XJ, He LC, Leung JCS, Kwok AWL, Griffith JF, Kwok T, Leung PC, Wáng YX. Osteoporotic vertebral fracture prevalence in elderly chinese men and women: a comparison of endplate/cortex fracture-based and morphometrical deformity-based methods. J Clin Densitom 2019;22:409-19.

57. Lauridsen KN, De Carvalho A, Andersen AH. Degree of vertebral wedging of the dorso-lumbar spine. Acta Radiol Diagn (Stockh) 1984;25:29-32.

58. Matsumoto M, Okada E, Kaneko Y, Ichihara D, Watanabe K, Chiba K, Toyama Y, Fujiwara H, Momoshima S, Nishiwaki Y, Hashimoto T, Takahata T. Wedging of vertebral bodies at the thoracolumbar junction in asymptomatic healthy subjects on magnetic resonance imaging. Surg Radiol Anat 2011;33:223-8.

59. Wang XR, Xu FR, Huang QL, Wáng YXJ. Radiological features of traumatic vertebral endplate fracture: an analysis of 194 cases with 263 vertebral fractures. Chin Med J (Engl) 2020. [Epub ahead of print]. doi: 10.1097/ CM9.0000000000000919.

60. Szulc P, Munoz F, Marchand F, Delmas PD. Semiquantitative evaluation of prevalent vertebral deformities in men and their relationship with osteoporosis: the MINOS study. Osteoporos Int 2001;12:302-10.

61. Ismail AA, O'Neill TW, Cooper C, Silman AJ, The European Vertebral Osteoporosis Study Group. Risk factors for vertebral deformities in men: relationship of number of vertebral deformities. J Bone Miner Res 2000;15:278-83.

62. Jackson SA, Tenenhouse A, Robertson L. Vertebral fracture definition from population-based data: preliminary results from the Canadian Multicenter Osteoporosis Study (CaMos). Osteoporos Int 2000;11:680-7.

63. Jiang G, Eastell R, Barrington NA, Ferrar L. Comparison of methods for the visual identification of prevalent vertebral fracture in osteoporosis. Osteoporos Int 2004;15:887-96.

64. Kim YJ, Chae SU, Kim GD, Park KH, Lee YS, Lee HY. Radiographic detection of osteoporotic vertebral fracture without collapse. J Bone Metab 2013;20:89-94.

65. Wáng YX, Santiago RF, Deng M, Nogueira-Barbosa MH. Identifying osteoporotic vertebral endplate and cortex fractures. Quant Imaging Med Surg 2017;7:555-91.

66. Wáng YX, Deng M, He LC, Che-Nordin MN, Santiago RF. Osteoporotic vertebral endplate and cortex fractures: a pictorial review. J Orthop Translat 2018;15:35-49. 
67. Lentle BC, Berger C, Probyn L, Brown JP, Langsetmo L, Fine B, Lian K, Shergill AK, Trollip J, Jackson S, Leslie WD, Prior JC, Kaiser SM, Hanley DA, Adachi JD, Towheed T, Davison KS, Cheung AM, Goltzman D; CaMos Research Group. Comparative Analysis of the radiology of osteoporotic vertebral fractures in women and men: cross-sectional and longitudinal observations from the Canadian Multicentre Osteoporosis Study (CaMos). J Bone Miner Res 2018;33:569-79.

68. Ferrar L, Jiang G, Adams J, Eastell R. Identification of vertebral fractures: an update. Osteoporos Int 2005;16:717-28.

69. Deng M, Kwok TCY, Leung JCS, Leung PC, Wáng YX. All osteoporotically deformed vertebrae with $>34 \%$ height loss have radiographically identifiable endplate/cortex fracture. J Orthop Translat 2018;14:63-6.

70. Wáng YX, Wang XR, Che-Nordin N, Xu FR, Huang QL. On the possibility of over-diagnosis of osteoporotic vertebral fracture at mid-thoracic level. J Thorac Dis 2019;11:5708-11.

71. Abdel-Hamid Osman A, Bassiouni H, Koutri R, Nijs J, Geusens P, Dequeker J. Aging of the thoracic spine: distinction between wedging in osteoarthritis and fracture in osteoporosis--a cross-sectional and longitudinal study. Bone 1994;15:437-42.

72. Cawthon PM, Haslam J, Fullman R, Peters KW, Black D, Ensrud KE, Cummings SR, Orwoll ES, Barrett-Connor E, Marshall L, Steiger P, Schousboe JT; Osteoporotic Fractures in Men (MrOS) Research Group. Methods and reliability of radiographic vertebral fracture detection in older men: the osteoporotic fractures in men study. Bone 2014;67:152-5.

73. Du MM, Che-Nordin N, Ye PP, Qiu SW, Yan ZH, Wáng YX. Underreporting characteristics of osteoporotic vertebral fracture in back pain clinic patients of a tertiary hospital in China. J Orthop Translat 2019. [Epub ahead of print]. doi: 10.1016/j.jot.2019.10.007.

74. Wáng YX. A modified semi-quantitative (mSQ) grading scheme for osteoporotic vertebral fracture in elderly women. Quant Imaging Med Surg 2019;9:146-50.

75. Wáng YX, Che-Nordin N. Some radiographically 'occult' osteoporotic vertebral fractures can be evidential if we look carefully. Quant Imaging Med Surg 2019;9:1992-5.

76. Hopkins RB, Pullenayegum E, Goeree R, Adachi JD, Papaioannou A, Leslie WD, Tarride JE, Thabane L. Estimation of the lifetime risk of hip fracture for women and men in Canada. Osteoporos Int 2012;23:921-7.

77. Schuit SC, van der Klift M, Weel AE, de Laet CE, Burger
H, Seeman E, Hofman A, Uitterlinden AG, van Leeuwen JP, Pols HA. Fracture incidence and association with bone mineral density in elderly men and women: the Rotterdam Study. Bone 2004;34:195-202.

78. Nguyen ND, Pongchaiyakul C, Center JR, Eisman JA, Nguyen TV. Identification of high-risk individuals for hip fracture: a 14-year prospective study. J Bone Miner Res 2005;20:1921-8.

79. Johnell O, Kanis JA, Oden A, Johansson H, De Laet C, Delmas P, Eisman JA, Fujiwara S, Kroger H, Mellstrom D, Meunier PJ, Melton LJ III, O’Neill T, Pols H, Reeve J, Silman A, Tenenhouse A. Predictive value of BMD for hip and other fractures. J Bone Miner Res 2005;20:1185-94.

80. Cummings SR, Cawthon P, Ensrud K, Cauley J, Fink H, Orwoll E. BMD and risk of hip and nonvertebral fractures in older men: a prospective study and comparison with older women. J Bone Miner Res 2006;21:1550-6.

81. Shin MH, Zmuda JM, Barrett-Connor E, Sheu Y, Patrick AL, Leung PC, Kwok A, Kweon SS, Nam HS, Cauley JA; Osteoporotic Fractures in Men (MrOS) Research Group. Race/ethnic differences in associations between bone mineral density and fracture history in older men. Osteoporos Int 2014;25:837-45.

82. Nam HS, Shin MH, Zmuda JM, Leung PC, BarrettConnor E, Orwoll ES, Cauley JA. Race/ethnic differences in bone mineral densities in older men. Osteoporos Int 2010;21:2115-23.

83. Lauderdale DS, Jacobsen SJ, Furner SE, Levy PS, Brody JA, Goldberg J. Hip fracture incidence among elderly Asian-American populations. Am J Epidemiol 1997;146:502-9.

84. Wright NC, Saag KG, Curtis JR, Smith WK, Kilgore ML, Morrisey MA, Yun H, Zhang J, Delzell ES. Recent trends in hip fracture rates by race/ethnicity among older US adults. J Bone Miner Res 2012;27:2325-32.

85. Sheu Y, Cauley JA, Wheeler VW, Patrick AL, Bunker $\mathrm{CH}$, Ensrud KE, Orwoll ES, Zmuda JM; Osteoporotic Fracture in Men (MrOS) Research Group. Age-related decline in bone density among ethnically diverse older men. Osteoporos Int 2011;22:599-605.

86. Kwok AW, Gong JS, Wang YX, Leung JC, Kwok T, Griffith JF, Leung PC. Prevalence and risk factors of radiographic vertebral fractures in elderly Chinese men and women: results of Mr. OS (Hong Kong) and Ms. OS (Hong Kong) studies. Osteoporos Int 2013;24:877-85.

87. Wang YX, Káplár Z, Deng M, Leung JCS. Lumbar degenerative spondylolisthesis epidemiology: A systematic review with a focus on gender-specific and age-specific 
prevalence. J Orthop Translat 2016;11:39-52.

88. Káplár Z, Wáng YX. South Korean degenerative spondylolisthesis patients had surgical treatment at earlier age than Japanese, American, and European patients: a published literature observation. Quant Imaging Med Surg 2016;6:785-90.

89. O’Neill TW, Felsenberg D, Varlow J, Cooper C, Kanis JA, Silman AJ. The prevalence of vertebral deformity in European men and women: the European Vertebral Osteoporosis Study. J Bone Miner Res 1996;11:1010-8.

90. Van der Klift M, De Laet CE, McCloskey EV, Hofman A, Pols HA. The incidence of vertebral fractures in men and women: the Rotterdam Study. J Bone Miner Res. 2002;17:1051-6.

Cite this article as: Wáng YXJ, Lentle BC. Radiographic osteoporotic vertebral fractures in elderly men: a brief review focusing on differences between the sexes. Quant Imaging Med Surg 2020;10(9):1863-1876. doi: 10.21037/qims-2020-21
91. European Prospective Osteoporosis Study (EPOS) Group, Felsenberg D, Silman AJ, Lunt M, Armbrecht G, Ismail AA, Finn JD, Cockerill WC, Banzer D, Benevolenskaya LI, Bhalla A, Bruges Armas J, Cannata JB, Cooper C, Dequeker J, Eastell R, Felsch B, Gowin W, Havelka S, Hoszowski K, Jajic I, Janott J, Johnell O, Kanis JA, Kragl G, Lopes Vaz A, Lorenc R, Lyritis G, Masaryk P, Matthis C, Miazgowski T, Parisi G, Pols HA, Poor G, Raspe HH, Reid DM, Reisinger W, Schedit-Nave C, Stepan JJ, Todd CJ, Weber K, Woolf AD, Yershova OB, Reeve J, O'Neill TW. Incidence of vertebral fracture in Europe: results from the European Prospective Osteoporosis Study (EPOS). J Bone Miner Res 2002;17:716-24. 